\title{
THE NOVEMBER MEETING IN WINSTON-SALEM
}

The five hundred and sixty-first meeting of the American Mathematical Society was held at Wake Forest College in Winston-Salem, North Carolina, on Friday and Saturday, November 20, 21, 1959. About eighty persons registered, including 64 members of the Society.

By invitation of the Committee to Select Hour Speakers for Southeastern Sectional Meetings, Professor Trevor Evans of Emory University addressed the Society on Friday on the topic, Decision problems in algebra. Professor R. D. Anderson presided at this session.

There were two sessions for contributed papers Friday afternoon and two on Saturday morning with Professors J. H. Curtiss, J. H. Roberts, T. L. Wade, and Henry Sharp presiding.

Paper number 561-7 was presented by R. A. Bradley. Mr. Bradley was introduced by Professor T. L. Wade and Mr. R. F. McCoart was introduced by Professor A. T. Brauer.

Members of the Society and their friends were entertained at a tea on Friday afternoon and there was a banquet Friday evening.

G. B. HuFf, Associate Secretary 